\title{
Effect of Antiadherents on the Physical and Drug Release Properties of Acrylic Polymeric Films
}

\author{
Hussein O. Ammar, ${ }^{1,4}$ Mamdouh M. Ghorab, ${ }^{2}$ Linda A. Felton, ${ }^{3}$ Shadeed Gad, ${ }^{2}$ and Aya A. Fouly ${ }^{1}$
}

Received 6 May 2015; accepted 7 August 2015; published online 28 August 2015

\begin{abstract}
Antiadherents are used to decrease tackiness of a polymer coating during both processing and subsequent storage. Despite being a common excipient in coating formulae, antiadherents may affect mechanical properties of the coating film as well as drug release from film-coated tablets, but how could addition of antiadherents affect these properties and to what extent and is there a relation between the physical characteristics of the tablet coat and the drug release mechanisms? The aim of this study was to evaluate physical characteristics of films containing different amounts of the antiadherents talc, glyceryl monostearate, and PlasACRYL ${ }^{\mathrm{TM}}$ T20. Eudragit RL30D and Eudragit RS30D as sustained release polymers and Eudragit FS30D as a delayed release material were used. Polymer films were characterized by tensile testing, differential scanning calorimetry (DSC), microscopic examination, and water content as calculated from loss on drying. The effect of antiadherents on in vitro drug release for the model acetylsalicylic acid tablets coated with Eudragit FS30D was also determined. Increasing talc concentration was found to decrease the ability of the polymer films to resist mechanical stress. In contrast, glyceryl monostearate (GMS) and PlasACRYL produced more elastic films. Talc at concentrations higher than $25 \%$ caused negative effects, which make $25 \%$ concentration recommended to be used with acrylic polymers. All antiadherents delayed the drug release at all coating levels; hence, different tailoring of drug release may be achieved by adjusting antiadherent concentration with coating level.
\end{abstract}

KEY WORDS: antiadherents; drug release; Eudragit polymers; film coating; mechanical properties.

\section{INTRODUCTION}

Coating has different functional, protective, and decorative purposes and is an important step during manufacturing of solid dosage forms. Polymeric film coating can be used to improve the quality, safety, operational efficiency, and production capability and increase profits (1). Despite of having more difficult film formation process than solvent-based solutions, aqueous polymeric dispersions have been used more frequently due to their lower toxicity levels (2). These aqueous-based polymers include acrylic resins, cellulosic derivatives, and vinyl polymers. Current study employed the acrylic polymers Eudragit RL30D (ERL), RS30D (ERS), and FS30D (EFS) as model coating polymers covering both delayed and sustained release. The presence of cationic quaternary ammonium groups (QAGs) in the chemical structure of the ERL and ERS influence the permeability of these water-insoluble

\footnotetext{
${ }^{1}$ Department of Pharmaceutical Technology, Faculty of Pharmaceutical Sciences and Pharmaceutical Industries, Future University in Egypt, Cairo, Egypt.

${ }^{2}$ Department of Pharmaceutics, Faculty of Pharmacy, Suez Canal University, Ismaiilia, Egypt.

${ }^{3}$ Department of Pharmaceutical Sciences, College of Pharmacy, University of New Mexico, Albuquerque, New Mexico, USA.

${ }^{4}$ To whom correspondence should be addressed. (e-mail: drhusseinammar@hotmail.com; husseinammar@fue.edu.eg)
}

polymers which makes them primarily used for sustained release applications (3-6). In contrast, the ionizable carboxylic acid functional groups present in EFS makes it suitable for delayed release (7-11).

Tackiness is an important issue during/after coating as the coating layer may become tacky before or after drying depending on its glass transition temperature $\left(T_{\mathrm{g}}\right)(12)$. So, antiadherents are added to the coating formulation. Most frequently, talc is used to decrease tackiness and is recommended for use with acrylic polymers (13). However, the addition of talc in coating formulations can result in sedimentation of the material during the spraying process, clogging of the spray nozzle, and incompatibilities with other materials in the coating and/or the substrate (14-18). Glyceryl monostearate $(G M S)$ has been used as an alternative to talc $(2,19,20)$. Another alternative is the ready-to-use PlasACRYLTM, a commercially available suspension of GMS, triethyl citrate as a plasticizer, and polysorbate 80 as a surfactant $(13,21)$.

The study depends on comparing between different antiadherents either in its common form such as talc and GMS or in a complete system such as PlasACRYL which combines antiadherent along with surfactant and plasticizer, such comparison would give us a chance to evaluate such ready-to-use systems against common antiadherents.

Physical-mechanical properties of polymeric films are important for their performance either in drug release or integrity of the final dosage forms and are strongly 
influenced by the presence of additives as previously reported by Felton et al. (22) and Fukui et al. (23). Thus, while antiadherents are necessary excipients in acrylic films, they may adversely affect polymer properties. The aim of this study was to determine the effect of different antiadherents on the physical-mechanical properties of acrylic polymer films and to correlate their effect on film properties to drug release of acetylsalicylic acid tablets as a model system.

\section{MATERIALS AND METHODS}

\section{Materials}

Poly(ethyl acrylate-co-methyl methacrylate-co-trimethyl ammonioethyl methacrylate chloride) 1:2:0.1 (ERS), poly(ethyl acrylate-co-methyl methacrylate-co-trimethyl ammonioethyl methacrylate chloride) 1:2:0.2 (ERL), poly(methyl acrylate-co-methyl methacrylate-co-methacrylic acid) 7:3:1 (EFS), and PlasACRYL ${ }^{\mathrm{TM}}$ T20 $(20 \%$ aqueous suspension, containing $G M S$ as antitacking agent, triethyl citrate as plasticizer, and polysorbate 80 as stabilizer) were kindly donated by Evonic Industries, Darmstadt, Germany. Triethyl citrate PG/NF (TEC; Citroflex-2) was supplied by Vertellus, Performance Materials Inc. NC, USA. Purified talc powder was purchased from El Gomhouria Co. Cairo, Egypt. Capmul GMS-50K was kindly donated by ABITEC Corporation. Aspirin $\circledast$ tablets $325 \mathrm{mg}$ were purchased from a Walgreens Pharmacy in Albuquerque, NM, USA and were coated with the EFS formulations. Additionally, Aspirin protect ${ }^{\circledR} 100 \mathrm{mg}$ tablets from BAYER (Cairo, Egypt) were purchased for comparative dissolution testing. Concentrated hydrochloric acid was from Pure, Adwic, Egypt, trisodium orthophosphate (dodecahydrate) extra pure from Lobachemi, India, sodium hydroxide flakes from Biotech for Laboratory Chemicals, Egypt, and Teflon protective overlay (BytacType VF-81) from Norton Performance Plastics Co., Akron, OH, USA.

\section{Methods}

\section{Preparation of Coating Suspensions}

Talc at concentrations of $25 \%, 50 \%$, and $100 \% \mathrm{w} / \mathrm{w}$, based on dry polymer weight, was dispersed in water at room temperature using a homogenizer. GMS at three different concentrations $(2 \%, 5 \%$, and $10 \% \mathrm{w} / \mathrm{w}$, based on dry polymer weight) was dispersed in distilled water at $70^{\circ} \mathrm{C}\left(10^{\circ} \mathrm{C}\right.$ above its melting point (24)) using tissue aerator homogenizer for 10 min then left to cool down to room temperature. PlasACRYL ( $10 \%$ and $20 \% \mathrm{w} / \mathrm{w}$, based on dry polymer weight) was dispersed in water at room temperature using a magnetic stirrer for $10 \mathrm{~min}$. The polymer dispersions were then added to the antiadherent-water mixtures and stirred with a magnetic stirrer. Next, the polymer dispersions were plasticized using TEC $(20 \% w / w$ based on dry polymer weight for ERL or ERS polymers and $10 \%$ for EFS polymer as it has low $T_{\mathrm{g}}$ and produced very sticky films with higher TEC concentrations (25)) for at least $1 \mathrm{~h}$ to ensure sufficient plasticization of the polymer. TEC was used at decreasing concentrations upon increasing PlasACRYL concentration in order to take account for the TEC which is already present in the ready-to-use PlasACRYL (control formula 0\% PlasACRYL-20\% TEC,
$10 \%$ PlasACRYL-15\% TEC, and 20\% PlasACRYL-10\% TEC formulae were used). Water was then added to the dispersions to adjust the total solid content to $15 \%(w / w)$. Composition of the prepared formulae is illustrated in Table I.

\section{Cast Polymer Films}

A modification of the conventional casting on glass or Teflon was used to prepare the free films (26). A Teflon island system was constructed of two Teflon pieces $12.0 \times 12.0 \mathrm{~cm}^{2}$ surrounded by four Teflon edges each $1 \mathrm{~cm}$ in width attached to a glass plate. The polymer dispersion was then cast across the system to aid in the removal of the formed film and in minimizing shrinking back after casting. The glass plates were stored in a leveled preheated oven for $24 \mathrm{~h}$ at $40^{\circ} \mathrm{C}$ and $50 \%$ relative humidity to allow for complete coalescence (27). The drying temperature was set to $10^{\circ} \mathrm{C}$ above the polymer's minimum film-forming temperature (28). Films were then carefully removed from the Teflon surfaces after cutting the edges with a scalpel.

\section{Characterization of the Prepared Polymer Films}

\section{Mechanical Testing of the Films}

The thickness of each film was measured at three different locations (center and two ends) using a digital micrometer. The mean value was calculated. Samples with a variation coefficient of the mean thickness measurements greater than $10 \%$ were discarded.

The mechanical properties of the films were evaluated using a Chatillon ${ }^{\circledR}$ DFGS50 digital force gauge and TCD200 motorized test stand. The tests were carried out with reference to ASTM specifications D882-02 (ASTM, 2002). At least six carefully inspected samples of each film were used. Each strip was fixed into the flat-faced grips of the instrument, with an initial length of $50 \mathrm{~mm}$ between the grips. The films were pulled apart at a rate of $20 \mathrm{~mm} / \mathrm{min}$ until the film strip broke. Force and deflection values were recorded on a computer. From the data, tensile strength $(\sigma)$ was calculated as stress at break divided by the initial cross-sectional area of the sample. Strain or elongation $(\varepsilon)$ was calculated as the increase in length divided by the original length of the film times 100. Young's modulus $(E)$ was calculated as the slope divided by (film thickness $\times$ cross-head speed), and work of failure was determined as the area under the stress versus strain graph

Table I. Composition of the Prepared Polymer Films

\begin{tabular}{llll}
\hline Polymer & $\begin{array}{c}\text { Eudragit } \\
\text { RL30D }\end{array}$ & $\begin{array}{c}\text { Eudragit } \\
\text { RS30D }\end{array}$ & $\begin{array}{r}\text { Eudragit } \\
\text { FS30D }\end{array}$ \\
\hline Antiadherent & & & \\
$\quad$ Talc & $25-100 \%$ & $25-100 \%$ & $25-100 \%$ \\
$\quad$ GMS & $2-10 \%$ & $5-10 \%$ & $2-10 \%$ \\
$\quad$ PlasACRYL & \\
Plasticizer & $10 \%$ & $10-20 \%$ & $10-20 \%$ \\
$\quad$ Triethyl citrate & $10-20 \%$ & $10-20 \%$ & $10 \%$ \\
\hline
\end{tabular}

Water was added in all formulations to reduce solids content to $15 \%$. All concentrations were calculated as percent $w / w$ based on the dry polymer weight 
multiplied by the cross-head speed $(\mathrm{mm} / \mathrm{s})$ divided by the cross-sectional area of the film (22). An additional parameter, the tensile strength/Young's modulus ratio $(\sigma / E)$ was also calculated as an indication of the crack resistance of the films (29).

\section{Thermal Analysis of the Films}

Small discs were cut from the previously prepared samples using a paper punch then precisely weighed $(10-15 \mathrm{mg})$ in aluminum pans. The pans were then hermetically sealed and subjected to differential scanning calorimetry (DSC) analysis (TA Instruments model 2920, New Castle, DE). The instrument was calibrated with indium. DSC thermograms were recorded under nitrogen flow rate of $20 \mathrm{~mL} / \mathrm{min}$ between a temperature range of $-20^{\circ} \mathrm{C}$ and $120^{\circ} \mathrm{C}$. An empty pan was used as a reference, and tests were done in triplicates. Thermograms were analyzed, and the glass transition temperature $\left(T_{\mathrm{g}}\right)$ was recorded as the midpoint of the transition that appeared in the total heat flow signal using TA Universal Analysis software.

\section{Loss on Drying}

Film strips were precisely weighed and kept for 60 days at $50^{\circ} \mathrm{C}$ in an oven and weighed frequently until weight was constant. Loss on drying (LOD) was then calculated as percentage from the total weight as follows:

$\%$ LOD $=($ initial weight - weight after drying $) \times 100$

\section{Tackiness Testing}

In order to investigate the effect of the additives on the tackiness of the polymer films, a T-peel test was used for tackiness measurement (30). Two film strips were put congruently on top of each other. At one end, double-sided Teflon tape was placed between the two films. The films were stored at $50 \%$ relative humidity and $40^{\circ} \mathrm{C}$, under a 500 -g weight for $3 \mathrm{~h}$ then cooled to room temperature $\left(23 \pm 2^{\circ} \mathrm{C}\right)$ for $1 \mathrm{~h}$ at $52 \%$ relative humidity.

A rigid tape was attached on the outer sides of the test films in order to avoid elongation of the polymer film during testing. The test specimens were placed with one end of each polymer film in two clamps (width $2.5 \mathrm{~cm}$ ) of the tensile testing device. The upper clamp was raised at a speed of $20 \mathrm{~mm} / \mathrm{min}$. The force required to separate the two polymer films was recorded. Three samples from each formulation were tested.

\section{Microscopic Examination}

Prepared films were examined under a light microscope for any defects or cracks. Images of the films containing the highest concentration of each antiadherent were captured and scanned into a computer for comparison.

\section{Statistical Analysis}

Data of mechanical testing were compared statistically using one-way analysis of variance (ANOVA). All mathematical calculations were undertaken with Microsoft Excel ${ }^{\circledR}$ (2010).

\section{Coating of Acetylsalicylic Acid Tablets}

Uncoated acetylsalicylic acid tablets containing $325 \mathrm{mg}$ of the drug were coated in a conventional coating pan. A batch size of 100 tablets was used, and tablets were collected to have the same weight $( \pm 1.5 \%)$ by weighing each tablet on a digital balance.

Prior to coating, the inner wall of the coating pan was sprayed with the same coating suspension used for each batch. Tablets were preheated for $10 \mathrm{~min}$ to reach a bed temperature of $30^{\circ} \mathrm{C}$. The coating dispersions were sprayed through a spray nozzle of $0.55 \mathrm{~mm}$ diameter (31). The atomization pressure was $1.8 \mathrm{bar}$, and the spray rate was $1 \mathrm{~g} / \mathrm{min}$. The spray gun was positioned $30 \mathrm{~cm}$ from the tablet bed surface, and drying temperature was adjusted to $10^{\circ} \mathrm{C}$ above the minimum filmforming temperature. The pan rotational speed was set at $30 \mathrm{rpm}$.

Tablets were coated to a theoretical polymer weight gain of $9 \mathrm{mg} / \mathrm{cm}^{2}$, with 20 tablets being withdrawn as samples at 3 and $6 \mathrm{mg} / \mathrm{cm}^{2}$ coating levels (32).

Delayed release formulae (EFS formulae) were used for coating so as to produce delayed release coated acetylsalicylic acid tablets with different types and concentrations of antiadherents; these formulae were chosen for coating as most of the coated tablets in the market are delayed release especially for patients with gastric implications from immediate release tablets (33). The coated tablets were then examined physically for cracks, air bubbles, or fissures and cured in an oven at $40^{\circ} \mathrm{C}$ for $24 \mathrm{~h}$ to allow coalescence of the film coating (34).

\section{In Vitro Dissolution Studies}

Calibration curves were constructed for the in vitro study at each time point (in order to normalize dissolution data for the unstable acetylsalicylic acid and to avoid error which may result from drug degradation): two in $0.1 \mathrm{~N} \mathrm{HCl}$ (for the acid stage) and six in $0.1 \mathrm{~N} \mathrm{HCl}: 0.2 \mathrm{M} \mathrm{Na}_{3} \mathrm{PO}_{4}$ (3:1), pH 7.4 (for the buffer stage) (35). Concentrations between 20 and $200 \mathrm{mcg} / \mathrm{mL}$ were prepared and measured spectrophotometrically (UV Spectrophotometer, Model UV-1800, Shimadzu, Japan) at wavelengths of 275 and $265 \mathrm{~nm}$ for the acid and the buffer stage, respectively $(33,36)$.

Drug release from film-coated tablets was conducted in $\mathrm{pH} 1.2(0.1 \mathrm{~N} \mathrm{HCl})$ for $2 \mathrm{~h}$ followed by $\mathrm{pH} 7.4$ (phosphate buffer) (36) using a USP paddle method (Dissolution Apparatus, Model Vision Elite 8, Hanson, USA), operated at $100 \mathrm{rpm}$ and $37^{\circ} \mathrm{C}$. The change in $\mathrm{pH}$ was done in situ by the addition of $250 \mathrm{~mL} 0.2 \mathrm{M}$ tribasic sodium phosphate to $750 \mathrm{~mL}$ $0.1 \mathrm{~N} \mathrm{HCl}$. Five-milliliter samples were withdrawn and replaced with fresh medium using an autosampler (Hanson Vision Heater and Hanson Vision Auto-fill, USA) at predetermined intervals up to $8 \mathrm{~h}$. Samples were then analyzed spectrophotometrically. The average of three replicates for each sampling point was calculated; dissolution efficiency 
(\%DE) was calculated and compared for dissolution data obtained each formula. Dissolution efficiency was calculated as the area under the dissolution curve within a time range $(\mathrm{t} 1-\mathrm{t} 2)(37)$.

\section{Assessment of the Similarity Factor Between Investigated and Marketed Coated Acetylsalicylic Acid Tablets}

Investigated coated tablets were compared to marketed delayed release acetylsalicylic acid tablets (Aspirin protect ${ }^{\circledR}$ $100 \mathrm{mg}$ ) in order to determine which of the prepared formulae will be closer to the marketed tablet release by calculating similarity factor F2 according to the equation:

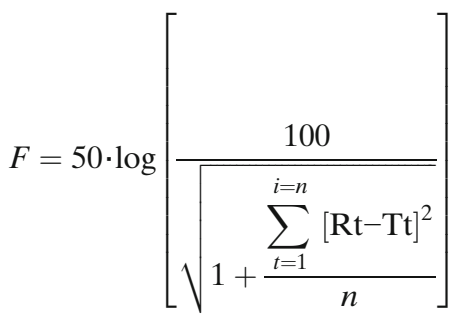

where $n$ is the number of time points, Rt is the dissolution value of the reference (formulation without antiadherents) batch at time $t$, and $\mathrm{Tt}$ is the dissolution value of the test formulations and a commercially available marketed product. A calculated F2 value of between 50 and 100 indicated similarity between the two dissolution profiles.

\section{RESULTS}

The effect of talc on the mechanical properties of the investigated acrylic polymer films is shown in Fig. 1. From this figure, it is apparent that increasing talc concentration led to increasing tensile strength and Young's modulus while decreasing both percentage strain at break and tensile strength to Young's modulus ratio.

Addition and increasing concentration of GMS was found to decrease tensile strength of ERL and ERS polymer films and increase percentage strain at break of ERL films while not affecting that of ERS films. An increase in the Young's modulus and a decrease in the tensile strength to Young's modulus ratio were also observed upon increasing the concentration of GMS as shown in Fig. 2.

Figure 3 shows the effect of addition and increase in PlasACRYL concentration which was an increase in film Young's modulus and a decrease in percentage strain at break and tensile strength to Young's modulus ratio of both ERL and ERS films. Tensile strength of ERL films was increased while that of ERS films was decreased upon the addition of PlasACRYL.

Figure 4 shows the effect of increasing concentration of the investigated antiadherents on the glass transition temperature of the polymer films. As shown in the figure, increasing antiadherent concentration led to an increase in the glass transition temperature of the films.

Figures 5 and 6 show the effect of talc and GMS, respectively, on the percentage loss on drying of the investigated polymer films which was found to be decreased upon increasing antiadherent concentration.

Tackiness of the ERL films was taken as a model to measure the effect of increasing talc concentration on the film tackiness. As shown in Fig. 7, it is apparent that tackiness decreases upon addition of talc in the formulation and reaches its minimum concentration at $25 \% \mathrm{w} / v$ (based on dry polymer weight) and that increasing talc concentration more than $25 \%$ $w / v$ did not show further decrease in the film tackiness.

Microscopic examination of the surface of the prepared polymer films (Fig. 8) reveals highest extent of defects with GMS. In contrast, PlasACRYL showed less imperfections and defects in the film appearance. Interestingly, talc showed the most homogenous appearance and least imperfections.

In vitro dissolution testing profiles are shown in Fig. 9. As shown in the figure, no drug release was observed in the acidic medium in all formulations. At a coating level of $9 \mathrm{mg} / \mathrm{cm}^{2}$, only about $25 \%$ of the drug was released at $8 \mathrm{~h}$ in the control formulation (no antiadherent present). Lower coating levels (3 and $6 \mathrm{mg} / \mathrm{cm}^{2}$ ) allowed for about $60 \%$ of the drug released at $8 \mathrm{~h}$. Similar results were found in the formulations containing antiadherents, although even less drug was released at the highest coating level of $9 \mathrm{mg} / \mathrm{cm}^{2}$.

The effect of talc on release profile of acetylsalicylic acid from tablets coated with EFS at different coating levels is shown in Fig. 10. As shown in the figure, a delay in the drug release was observed upon increasing talc concentration at all coating levels.

The release profile of acetylsalicylic acid from marketed enteric coated tablets, Aspirin protect ${ }^{\circledR} 100 \mathrm{mg}$, is shown in Fig. 11. Results of the F2 test as a function of antiadherent and coating level are shown in Table II.

\section{DISCUSSION}

\section{Characterization of the Prepared Polymer Films}

\section{Mechanical Testing of the Films}

A mechanically strong polymer film will be able not only to resist mechanical damage during production and storage but also to avoid dose dumping through cracks which may occur in brittle polymer films $(28,38)$. Four different parameters were measured and calculated in order to set a complete mechanical profile for the prepared formulations: tensile strength, percentage strain at break, Young's modulus, and tensile strength to Young's modulus ratio, which gives an indication on strength, brittleness, stiffness, and resistance of the film to mechanical stress. As shown in Fig. 11, it is apparent that increasing concentration of talc in the films resulted in increased film brittleness and stiffness and decreased film toughness, irrespective of polymer type. These results were attributed to the presence of talc as solid particles which reduce polymer chain mobility due to steric hindrance (39). Parvin et al. (40) also found similar effects of talc on highdensity polyethylene polymer system. These results agree also with what was reported by Gibson et al. (41) that talc caused an increase in film brittleness and stiffness.

Unlike talc, the effect of GMS on the mechanical parameters of ERL and ERS was not consistent (Fig. 11). In ERL 
a

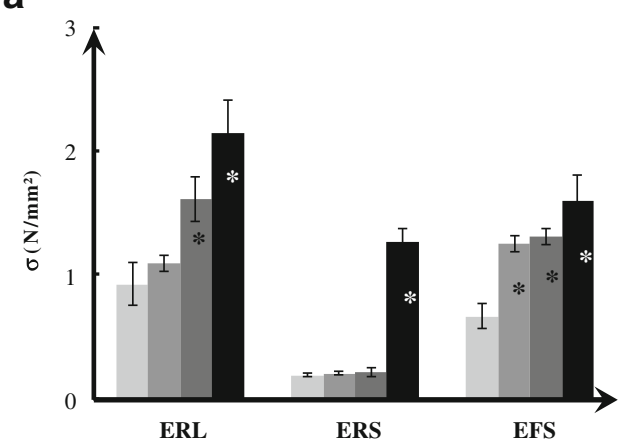

C

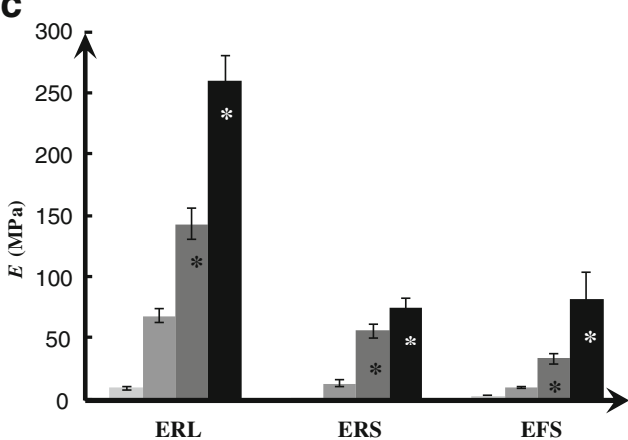

b

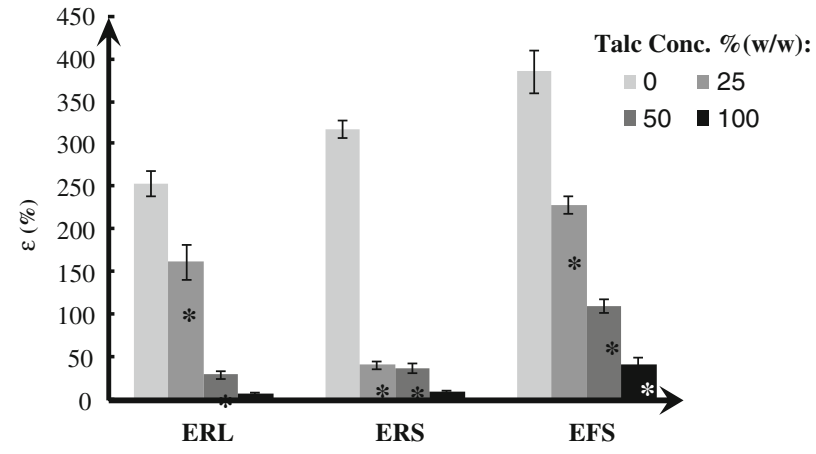

d

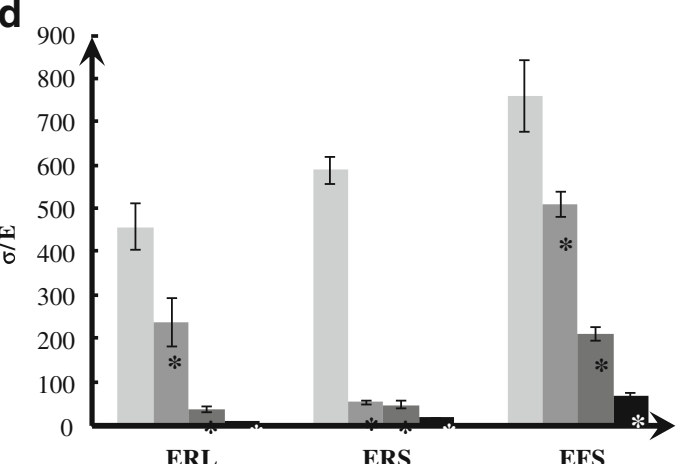

Fig. 1. Effect of talc concentration on a tensile strength $(\sigma)$, b strain at break $(\varepsilon)$, c Young's modulus $(E)$, and d tensile strength/Young's modulus ratio $(\sigma / E)$ of Eudragit ${ }^{\circledR}$ RL30D, Eudragit ${ }^{\circledR}$ RS30D, and Eudragit ${ }^{\circledR}$ FS30D polymer films. Asterisk: Significant difference (compared to $0 \%$ antiadherent of each film type at probability value of $P<0.001$ ) using one-way analysis of variance (ANOVA)

a

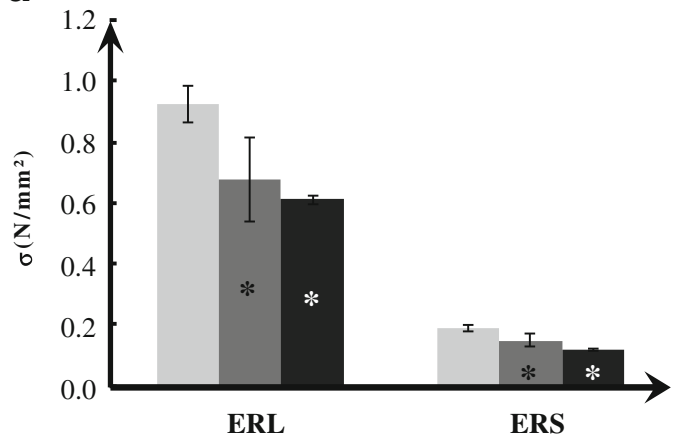

C

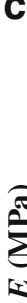

b

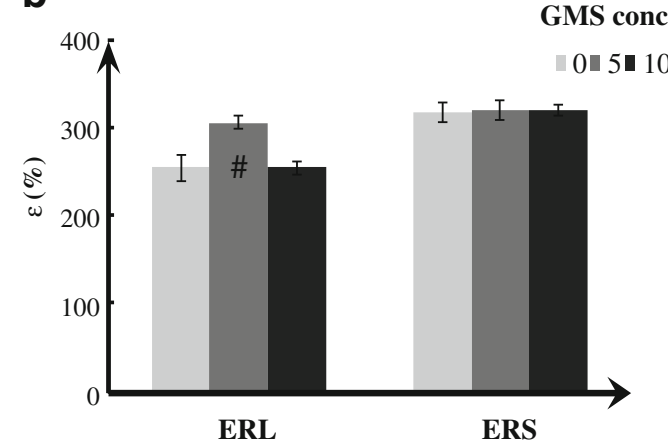

d

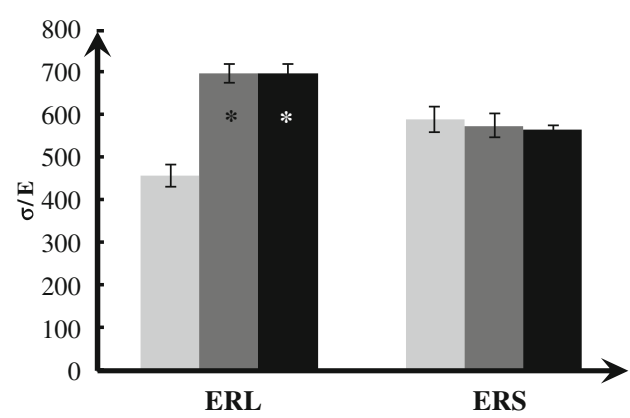

Fig. 2. Effect of glyceryl monostearate concentration on a tensile strength $(\sigma)$, b strain at break $(\varepsilon)$, c Young's modulus $(E)$, and d tensile strength/Young's modulus ratio $(\sigma / E)$ of Eudragit ${ }^{\circ}$ RL30D and Eudragit $\AA$ RS30D polymer films. Significant difference (compared to control at probability value of $P<0.001$ (asterisk) and at probability value of $P<0.05$ (number sign)) using one-way analysis of variance (ANOVA) 

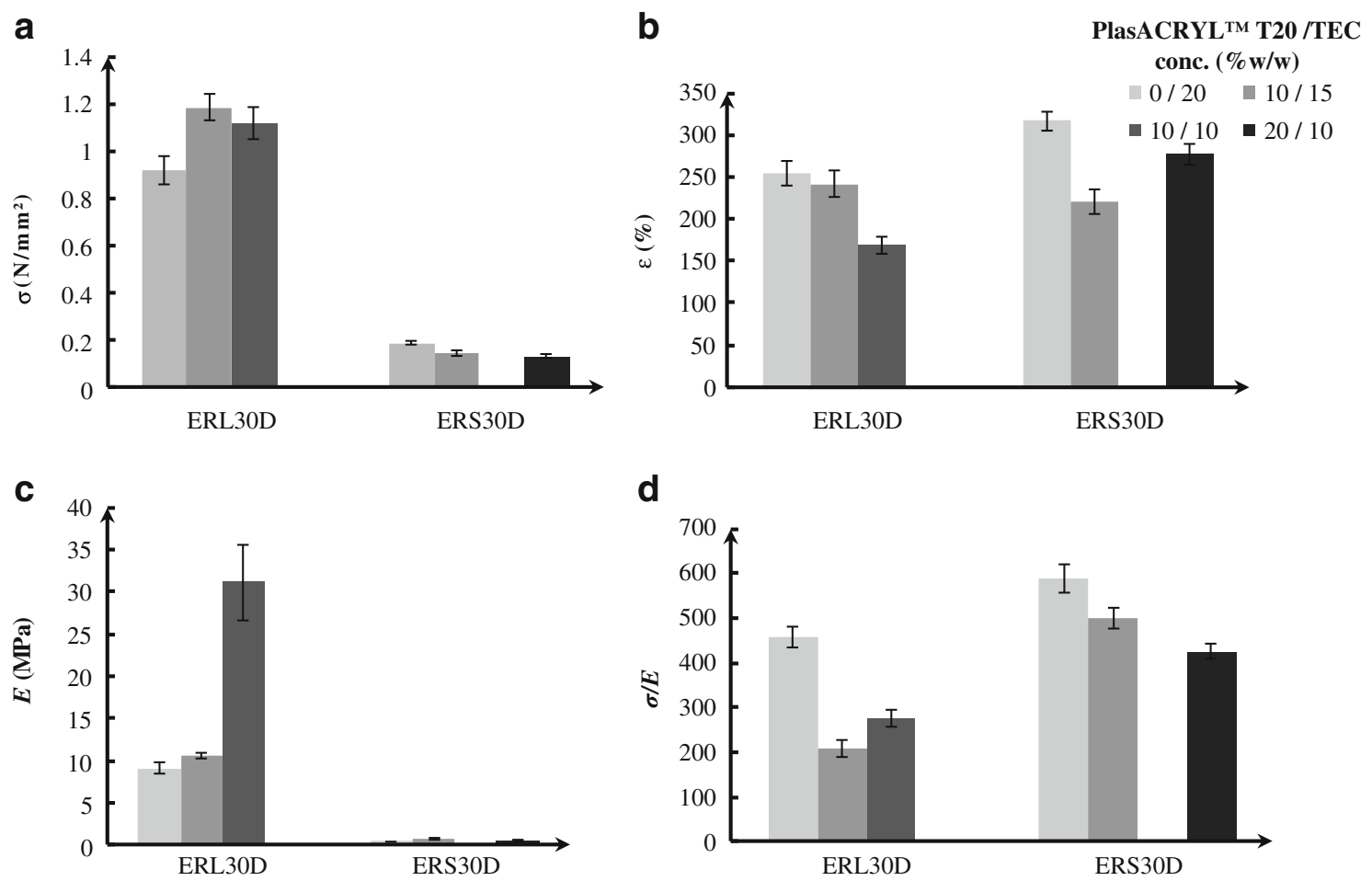

Fig. 3. Effect of PlasACRYL Tм T20 concentration on a tensile strength $(\sigma)$, b strain at break $(\varepsilon)$, $\mathbf{c}$ Young's modulus $(E)$, and d tensile strength/Young's modulus ratio $(\sigma / E)$ of Eudragit ${ }^{\circledR}$ RL30D and Eudragit ${ }^{\circledR}$ RS30D polymer films

films, a decrease in brittleness was observed with increasing amounts of GMS, whereas brittleness did not significantly change in ERS films. The difference in the degree of hydrophobicity between both polymers, Eudragit ${ }^{\circledR}$ RS30D > Eudragit ${ }^{\circledR}$ RL30D (42), may be responsible, as blending of the hydrophobic GMS particles with ERS polymer was better than that with ERL polymer because of the relative hydrophilicity of the latter polymer. These results are in agreement with findings previously reported by Nimkulrat et al. (2) that GMS is dispersed well in the polymer suspension because of its relative hydrophobicity. Such difference between GMS and talc effects on some parameters may be attributed to the difference in nature between both antiadherents as GMS characterized by its waxy nature (19). The rest of the parameters responded in the same way to GMS and to talc which means that GMS did not show much different effect than talc regarding stiffness of the films.

PlasACRYL was found to increase film stiffness and brittleness and to decrease toughness of both ERL and ERS films and as a consequence the work required to break those films. Tensile strength of ERL films was increased, while that of ERS films was decreased upon the addition of PlasACRYL as shown in Fig. 11. So, comparing PlasACRYL against GMS as an antiadherent, PlasACRYL was found to incorporate in the coating dispersion to a greater extent, likely due to the presence of the surfactant polysorbate 80 . This agrees with what was reported by Gaur et al. (43) that polysorbate 80 increased clarity of the GMS polymer dispersion.

In comparing the effects of antiadherents in the films, the concentration and type of antiadherent added to the coating formulation significantly changed the films from soft and tough to hard, brittle talc films or hard, strong GMS or PlasACRYL films.

\section{Thermal Analysis of the Films}

The glass transition temperature $\left(T_{\mathrm{g}}\right)$ is considered to be one of the most important properties determined for amorphous polymers (44). It is the temperature at which the mechanical properties of a polymer change from a brittle to a rubber state. Glass transition temperature gives an indication of changes in physical and chemical properties of the filmforming polymers and also on any potential incompatibility between the polymers and other additives in the dispersion. The effect of the investigated antiadherents on the $T_{\mathrm{g}}$ of the acrylic polymer films is shown in Fig. 11. Increasing antiadherent concentration led to significant increases in the $T_{\mathrm{g}}$ of ERL and ERS polymer films, as previously reported by Steward et al. (28), which indicates restrictions in the polymer chain mobility and decreasing elasticity of the polymer films and increasing internal stress of the films (22).

\section{Loss on Drying}

Water content of the films was measured through loss on drying experiment, and the percentage loss on drying (\%LOD) was calculated which may give an indication on in vivo release (an increase in residual water in the coating film indicates an increase in the water influx into the tablet and drug diffusion from the tablet as a consequence) (45). Increasing the concentration of talc and GMS in ERL and ERS films resulted in a decrease in the \%LOD of the 
a

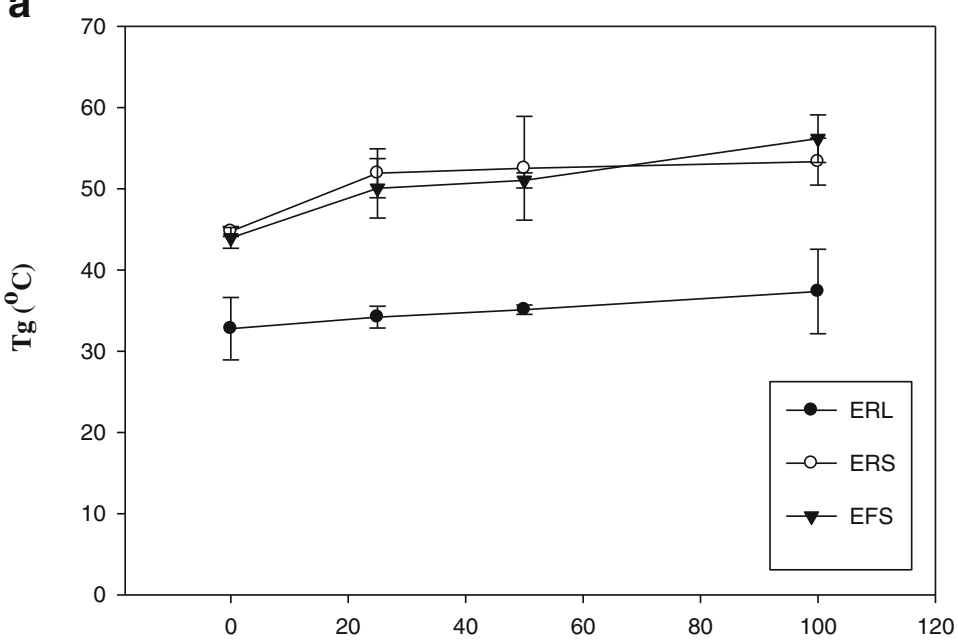

Talc Concentration \%w/w (based on dry polymer weight)

b

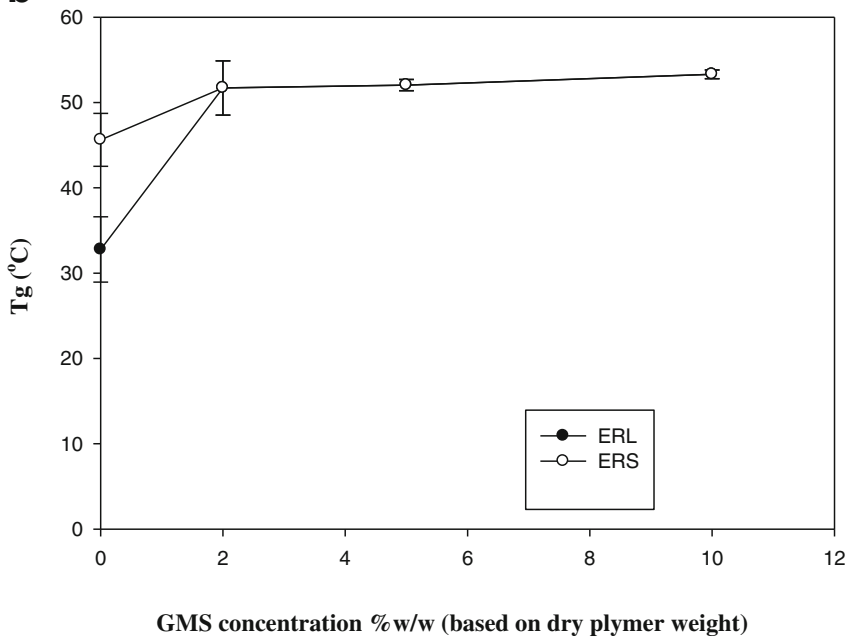

C

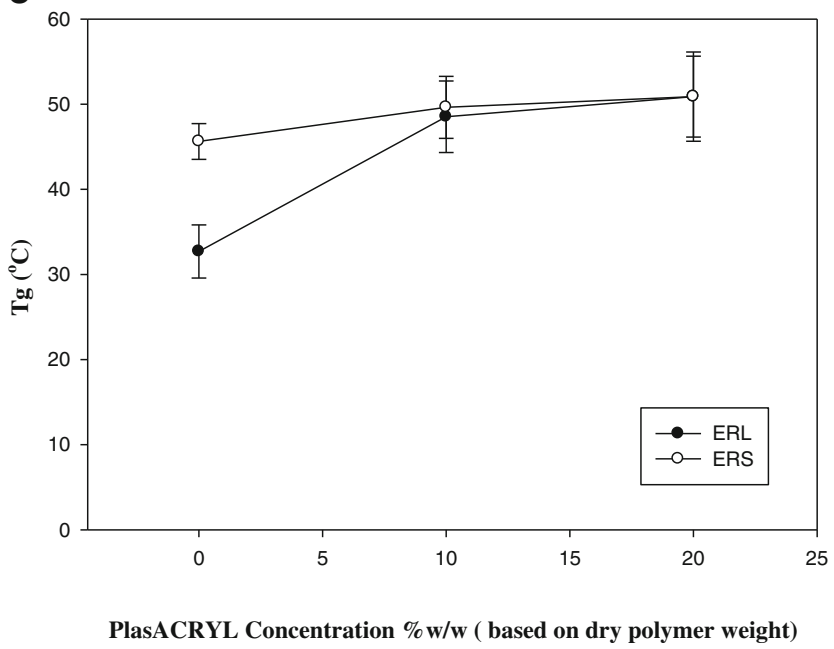

Fig. 4. Effect of antiadherents on the glass transition temperature of acrylic polymer films a talc (ERL, ERS (20\% TEC) and EFS (10\% TEC) polymer films), b glyceryl monostearate (20\% TEC), and c PlasACRYL (ERL and ERS polymer films (10\% PlasACRYL-15\% TEC and 20\% PlasACRYL-10\% TEC, consequently)

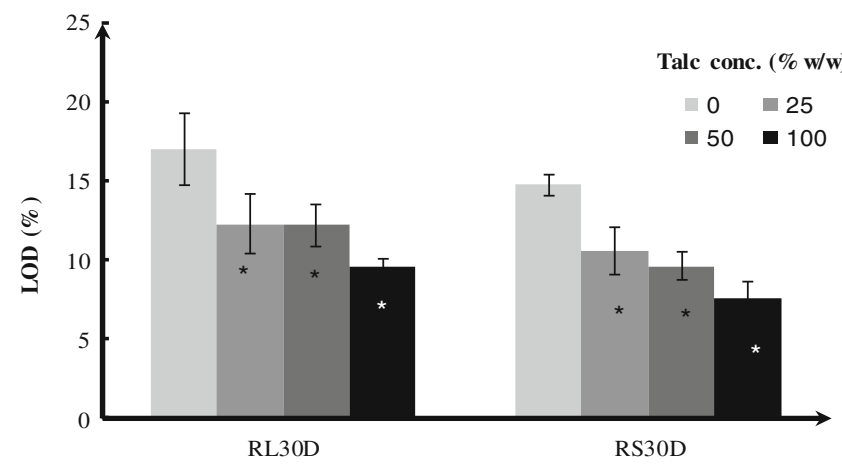

Fig. 5. Effect of talc on the percentage loss on drying of ERL and ERS films. Asterisk: One-way analysis of variance (ANOVA) was used for statistical analysis to determine the significant difference from control films of the same polymer concentration at probability value of $P<0.001$

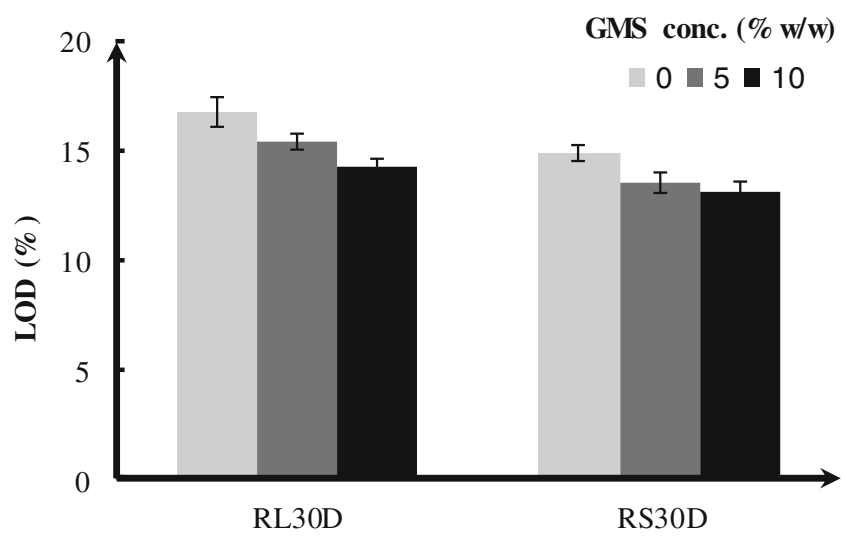

Fig. 6. Effect of glyceryl monostearate on the percentage loss on drying of ERL and ERS films 


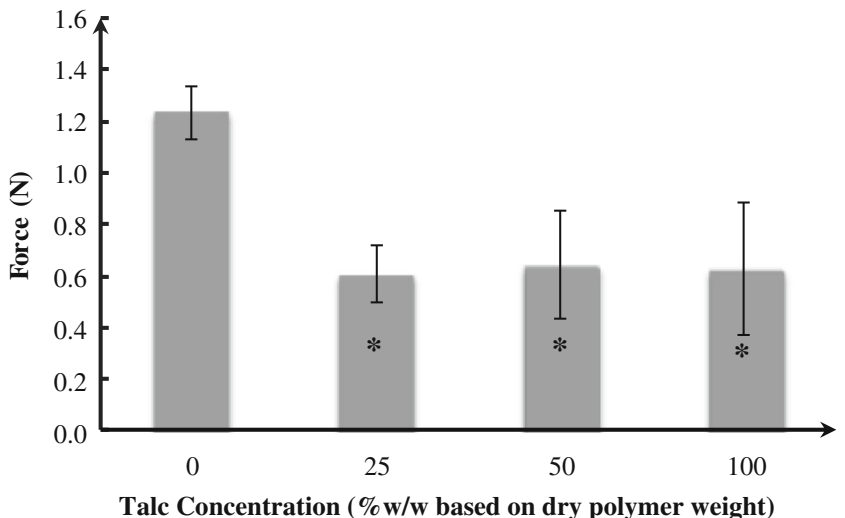

Fig. 7. Effect of talc on the tackiness of ERL polymer films. Asterisk: One-way analysis of variance (ANOVA) was used for statistical analysis to determine the significant difference from control films at a probability value of $P<0.001$ )

prepared polymer films (Fig. 11). So, films with higher levels of talc have less residual water, and these findings were attributed to the hydrophobic nature of the antiadherent that decrease was more significant with ERS which will as a consequence affect mechanical parameters of the films as water acts as a plasticizer (46-48).

\section{Tackiness Testing}

Eudragit RL30D-talc films were used as a model for testing tackiness as talc is the most commonly used antiadherent in coating formulations. In addition, the ERL was selected as the model acrylic polymer because of its reduced tackiness compared to ERS, and EFS as T-peel testing of films with a high degree of tackiness may result in failure of the test. Figure 11 demonstrates that talc at

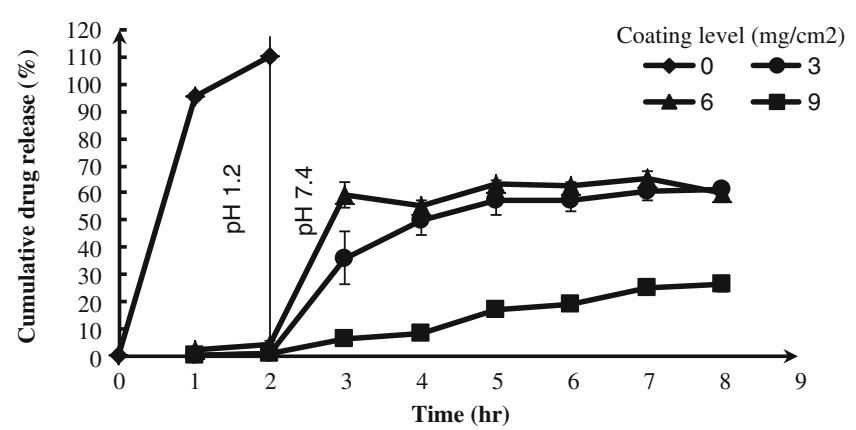

Fig. 9. Effect of coating level on the release profile of acetylsalicylic acid from tablets coated with EFS, $0 \%$ talc

$25 \%(w / w)$ concentration decreased significantly the tackiness of the films and that higher talc concentrations did not result in further decrease in tackiness of the films.

\section{Microscopic Examination}

Microscopic examination of the film was conducted to detect any abnormalities or defects. The morphology of the films showed significant changes in appearance, and from these micrographs, it can be concluded that the addition of antiadherents highly affects the apparent surface morphology of the films (Fig. 11). GMS showed the highest extent of defects. In contrast, Tween 80 in the PlasACRYL formula better homogenized the GMS in the polymer films, as evidenced by less imperfections and defects in the film appearance. Interestingly, talc showed the most homogenous appearance and least imperfections. This might be attributed to the size of the used talc particles (micronized talc) which would disperse better in the polymer dispersion.
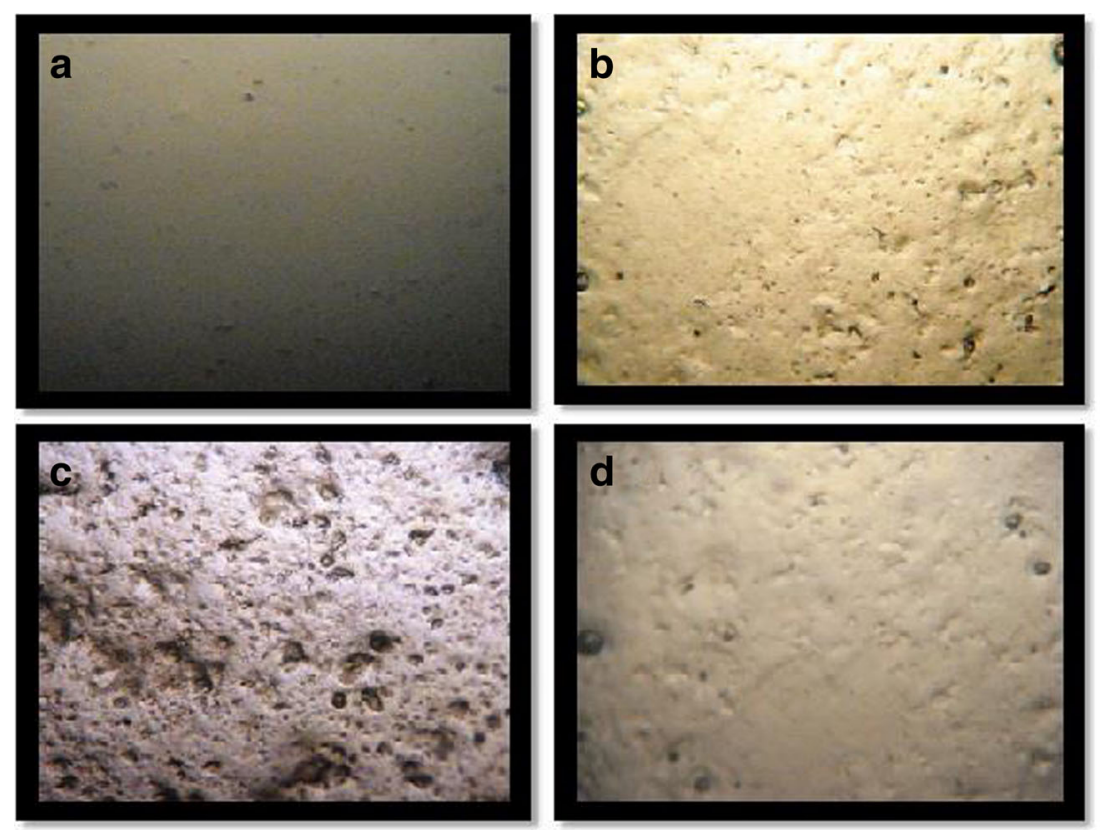

Fig. 8. Microscopic photographs $(\times 40)$ of the ERL polymer films: a $0 \%$ antiadherent, b $100 \%$ talc, c $10 \%$ glyceryl monostearate, and d $20 \%$ PlasACRYL 
a

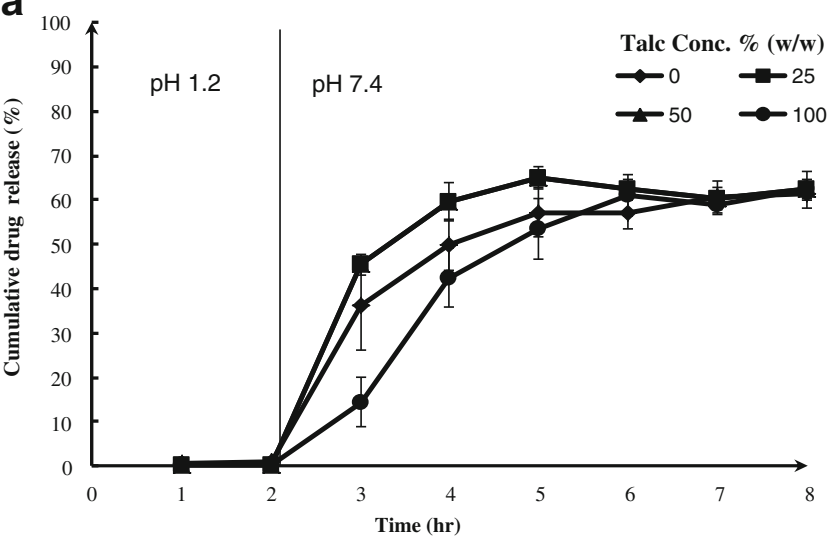

b

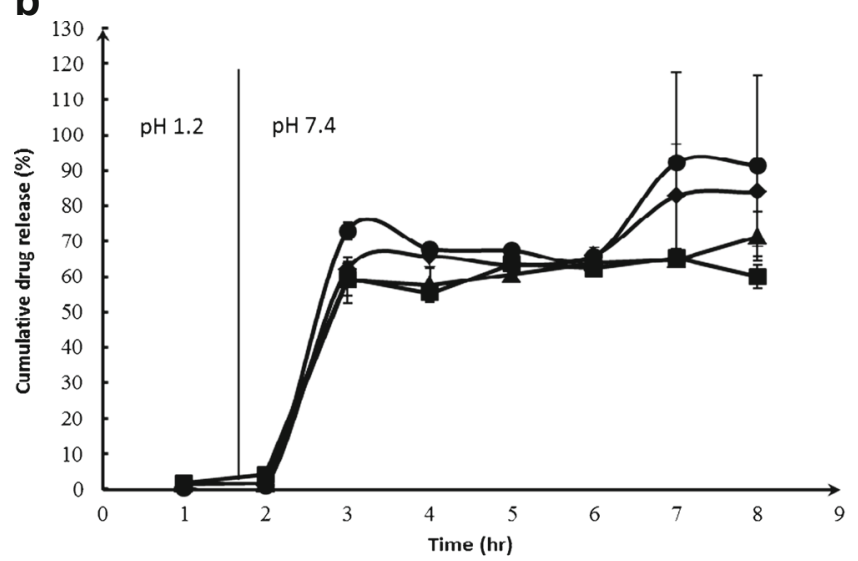

C

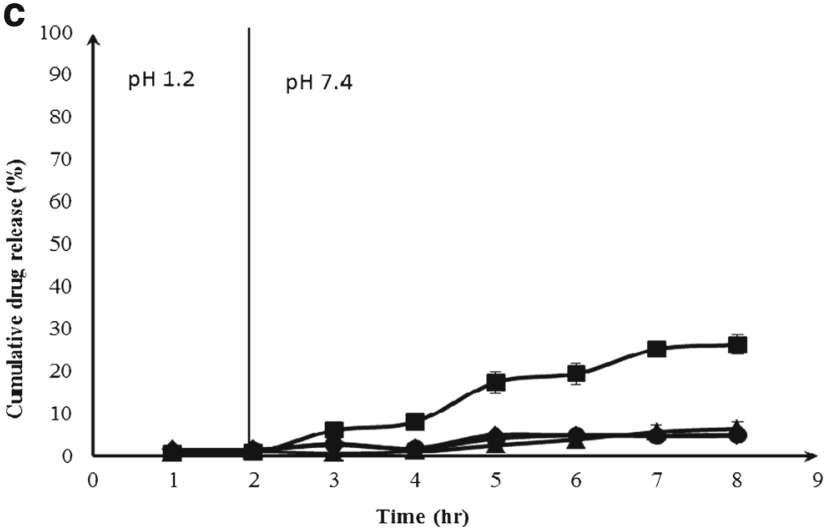

Fig. 10. Effect of talc on release profile of acetylsalicylic acid from tablets coated with EFS at a $3 \mathrm{mg} / \mathrm{cm}^{2}$, b $6 \mathrm{mg} / \mathrm{cm}^{2}$, and c $9 \mathrm{mg} / \mathrm{cm}^{2}$ coating levels

Assessment of the Effect of Antiadherents on the Release Profile of Acetylsalicylic Acid Tablets

In Vitro Release Profile of Acetylsalicylic Acid Delayed Release Tablets. Nine coating formulae were prepared using EFS as a delayed release model polymer, one control formula without antiadherent, while the other eight formulae covered the three investigated antiadherents; at the same concentrations used in the free film characterization studies: talc (0$100 \%)$, GMS (2-10\%), and PlasACRYL (10-20\%). All three

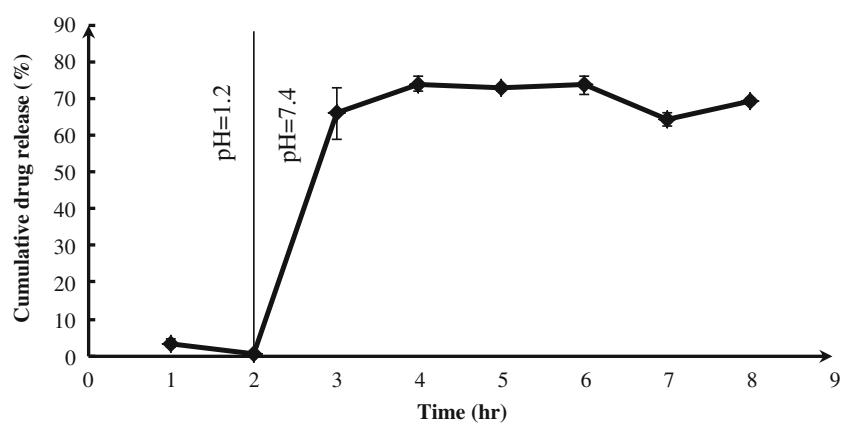

Fig. 11. Release profile of acetylsalicylic acid from marketed enteric coated tablets Aspirin protect ${ }^{\circledR} 100 \mathrm{mg}$

coating levels investigated with talc prevented drug release in the acidic medium. At the highest coating level, only about $25 \%$ of the drug was released at $8 \mathrm{~h}$ in the control formulation (no antiadherent present). Lower coating levels ( 3 and $6 \mathrm{mg} /$ $\mathrm{cm}^{2}$ ) allowed for about $60 \%$ of the drug released at $8 \mathrm{~h}$. Similar results were found in the formulations containing antiadherents, although even less drug was released at the highest coating level of $9 \mathrm{mg} / \mathrm{cm}^{2}$. These results indicate that enteric protection can be achieved at a minimum coating thickness of $3 \mathrm{mg} / \mathrm{cm}^{2}$. The study suggests making use of the high delay in the drug release upon increasing coating level by using those high coating levels to achieve sustained delayed release formula. Increasing antiadherent concentration showed delay in the drug release especially at the highest coating level.

\section{Assessment of the Similarity Factor Between Prepared and Marketed Coated Acetylsalicylic Acid Tablets}

Dissolution results from the current study were compared to a commercially available product using the F2 similarity test. The highest similarity was obtained at $6 \mathrm{mg} / \mathrm{cm}^{2}$ coating level with the talc formulae which ranged from $48 \%$ to $58 \%$ and at $3 \mathrm{mg} / \mathrm{cm}^{2}$ coating level with $G M S$ and PlasACRYL formulae which ranged from $43 \%$ to $57 \%$, while $9 \mathrm{mg} / \mathrm{cm}^{2}$ coating level showed the lowest $\mathrm{F} 2$ values.

Table II. Similarity Factor (F2) Values of Each of the Investigated Formulae with Marketed Coated Tablets

\begin{tabular}{llll}
\hline Formula & \multicolumn{3}{l}{ Coating level $(\mathrm{mg} / \mathrm{cm})^{2}$} \\
\cline { 2 - 4 } & 3 & 6 & 9 \\
\hline $0 \%$ antiadherent & 28.590 & 48.696 & 11.651 \\
$25 \%$ talc & 42.308 & 45.373 & 5.006 \\
$50 \%$ talc & 17.194 & 58.587 & 4.637 \\
$100 \%$ talc & 25.284 & 54.502 & 4.755 \\
\% GMS & 44.837 & 42.856 & 5.227 \\
10\% GMS & 54.045 & 44.208 & 5.305 \\
$10 \%$ PlasACRYL & 43.654 & 38.425 & 5.278 \\
$20 \%$ PlasACRYL & 57.982 & 46.815 & 21.362 \\
\hline
\end{tabular}




\section{Conclusion}

Although they are often important additives in the coating formulations, antiadherents may have dramatic effects on the physical characteristics and drug release properties of coated products. The current study showed that ERL, ERS, and EFS films were affected mechanically and thermally by the addition of talc, GMS, or PlasACRYL. Talc increased internal stress, stiffness, and brittleness while decreased the ability of the films to resist mechanical stress. GMS and PlasACRYL did not affect mechanical stress resistance of the films negatively as much as talc especially regarding film brittleness. GMS showed better combination with ERS regarding film brittleness and with ERL regarding film strength. Increasing antiadherent concentration caused a decrease in polymer mobility which was proven by a decrease in the elongation at break values and an increase in $T_{\mathrm{g}}$. Talc at $5 \%$ $w / w$ concentration showed the least significant effect on mechanical properties. Upon comparing the effect of PlaSACRYL to that of GMS on mechanical properties or on release profiles, it was found that it showed less negative effects which makes it a very good alternative for GMS. The obtained results reveal the existence of an evident relationship between the mechanical, thermal, and adhesive properties of the acrylic polymer films. Increasing antiadherent concentration especially at the highest coating level may be used in tailoring drug release in a delayed sustained release formulae instead of the conventional delayed release profile.

\section{REFERENCES}

1. Roy GM. Taste masking in oral pharmaceuticals. Pharm Technol. 1994;18:84-99.

2. Nimkulrat S, Suchiva K, Phinyocheep P, Puttipipatkhachorn S. Influence of selected surfactants on the tackiness of acrylic polymer films. Int J Pharm. 2004;287(1-2):27-37.

3. Maroni A, Del Curto MD, Zema L, Foppoli A, Gazzaniga A. Film coatings for oral colon delivery. Int J Pharm. 2013;457(2):372-94.

4. Moustafine RI, Bodrov AV, Kemenova VA, Rombaut P, Van den Mooter G. Drug release modification by interpolymer interaction between countercharged types of Eudragit(R) RL 30D and FS 30D in double-layer films. Int J Pharm. 2012;439(1-2):17-21.

5. INAL Ö, YAPAR AE, BAYKARA T. Physical properties and in vitro release studies on sotalol monolithic films prepared by Eudragit polymers. Turk J Pharm Sci. 2010;7(2):151-60.

6. Zelko R, Orban A, Suvegh K, Riedl Z, Racz I. Effect of plasticizer on the dynamic surface tension and the free volume of Eudragit systems. Int J Pharm. 2002;244(1-2):81-6.

7. Lehmann K. Chemistry and application properties of polymethacrylate coating systems. In: McGinity JW, editor. Aqueous polymeric coating for pharmaceutical dosage forms. New York: Marcel Dekker; 1998.

8. Coufal P, Stulik K, Claessens HA, Hardy MJ, Webb M. Separation and quantification of ropinirole and some impurities using capillary liquid chromatography. J Chromatogr B Biomed Sci Appl. 1999;732(2):437-44.

9. Ubaidulla U, Reddy MV, Ruckmani K, Ahmad FJ, Khar RK. Transdermal therapeutic system of carvedilol: effect of hydrophilic and hydrophobic matrix on in vitro and in vivo characteristics. AAPS PharmSciTech. 2007;8(1):2.

10. Kusum Devi V, Saisivam S, Maria GR, Deepti PU. Design and evaluation of matrix diffusion controlled transdermal patches of verapamil hydrochloride. Drug Dev Ind Pharm. 2003;29(5):495-503.

11. Lehmann K. Practical course in film coating of pharmaceutical dosage forms with Eudragit. Pharma Polymer: Darmstadt; 2001.
12. Felton LA. Characterization of coating systems. AAPS PharmSciTech. 2007;8(4):E112.

13. Nollenberger K, Albers J. Poly(meth)acrylate-based coatings. Int J Pharm. 2013;457(2):461-9.

14. Phadke DS, Keeney MP, Norris DA. Evaluation of batch-tobatch and manufacturer-to-manufacturer variability in the physical properties of talc and stearic acid. Drug Dev Ind Pharm. 1994;20:859-71.

15. Felton LA, McGinity JW. Adhesion of polymeric films to pharmaceutical solids. Eur J Pharm Biopharm. 1999;47(1):3-14.

16. Wu C, McGinity JW. Influence of an enteric polymer on drug release rates of theophylline from pellets coated with Eudragit RS 30D. Pharm Dev Technol. 2003;8(1):103-10.

17. Maejima T, McGinity JW. Influence of film additives on stabilizing drug release rates from pellets coated with acrylic polymers. Pharm Dev Technol. 2001;6(2):211-21.

18. Hamed E, Sakr A. Effect of curing conditions and plasticizer level on the release of highly lipophilic drug from coated multiparticulate drug delivery system. Pharm Dev Technol. 2003;8(4):397-407.

19. Petereit H-U, Assmus M, Lehmann K. Glyceryl monostearate as a glidant in aqueous film-coating formulations. Eur J Pharm Biopharm. 1995;41(4):219-28.

20. Ghosh S, Rousseau D. Freeze-thaw stability of water-in-oil emulsions. J Colloid Interface Sci. 2009;339(1):91-102.

21. Romeroa LM, Segundoa EP, Arzaluza MGN, Quintanara AG, Sánchezb SC, Guerreroa DQ. Comparison of pharmaceutical films prepared from aqueous polymeric dispersions using the cast method and the spraying technique. Colloids Surf A Physicochem Eng Asp. 2009;337:109-16.

22. O'Donnell PB, Felton LA, McGinity JW. Mechanical properties of polymeric films prepared from aqueous polymeric dispersions. In: McGinity JW, editor. Aqueous polymeric coating for pharmaceutical dosage forms. 79. 2nd ed. New York: Marcel Dekker; 1997. p. $517-48$.

23. Fukui E, Miyamura N, Yoneyama T, Kobayashi M. Drug release from and mechanical properties of press-coated tablets with hydroxypropylmethylcellulose acetate succinate and plasticizers in the outer shell. Int $\mathrm{J}$ Pharm. 2001;217(1-2):33-43.

24. Lehmann K. Coating of multiparticulates using polymeric solutions. In: Sellassie G, editor. Multiparticulate oral drug delivery. New York: Marcel Dekker; 1994. p. 51-78.

25. Radebaugh GW. Film Coatings and film-forming materials: evaluation. In: Swarbrick J, Boylan JC, editors. 6. New York: Marcel Dekker; 1993. p. 1-27.

26. Fanta GF, Selling GW, Felker FC, Kenar JA. Preparation and properties of films cast from mixtures of poly(vinyl alcohol) and submicron particles prepared from amylose-palmitic acid inclusion complexes. Carbohydr Polym. 2015;121:420-7.

27. Rohm Pharm Info Sheets, Rohm Pharm Polymer. Info sheets: O/E 2-4, 7.7/E 1-4, 7.9/E 1-4. Darmstadt: GmbH; 2002

28. Steward PA, Hearn J, Wilkinson MC. An overview of polymer latex film formation and properties. Adv Colloid Interface Sci. 2000;86(3):195-267.

29. Omari DM, Sallam A, Abd-Elbary A, El-Samaligy M. Lactic acid-induced modifications in films of Eudragit RL and RS aqueous dispersions. Int J Pharm. 2004;274(1-2):85-96.

30. Wesseling M, Kuppler F, Bodmeier R. Tackiness of acrylic and cellulosic polymer films used in the coating of solid dosage forms. Eur J Pharm Biopharm. 1999;47(1):73-8.

31. Felton LA. Film coating of oral solid dosage forms. In: Swarbrick J, editor. Encyclopedia of pharmaceutical technology. 1. 3rd ed. North Carolinia: PharmaceuTech, Inc; 2007.

32. Siepmann F, Siepmann J, Walther M, MacRae RJ, Bodmeier R. Polymer blends for controlled release coatings. J Control Release. 2008;125(1):1-15.

33. Wang Y, Xu P-P, Lia X-X, Nie K, Tuo M-F, Kong B, et al. Monitoring the hydrolyzation of aspirin during the dissolution testing for aspirin delayed-release tablets with afiber-optic dissolution system. J Pharm Anal. 2012;2(5):386-9.

34. Dashevsky A, Wagner K, Kolter K, Bodmeier R. Physicochemical and release properties of pellets coated with Kollicoat SR 30 $\mathrm{D}$, a new aqueous polyvinyl acetate dispersion for extended release. Int J Pharm. 2005;290(1-2):15-23. 
35. Lafferty SV, Newton JM, Podczeck F. Characterisation of the mechanical properties of polymer films formed from aqueous polymer dispersions by creep testing. Int J Pharm. 2002;239(1-2):143-8.

36. United States Pharmacopeia 36 online website [Internet]. 2013 [cited Accessed 12 Oct 2013.]. Available from: http://www.pharmacopeia.cn/v29240/usp29nf24s0_m6292.html.

37. Islam SMA, Islam S, Shahriar M, Dewan I. Comparative in vitro dissolution study of aceclofenac marketed tablets in two different dissolution media by validated analytical method. J Appl Pharm Sci. 2011;01(09):87-92.

38. Bhattacharjya S, Wurster DE. Investigation of the drug release and surface morphological properties of film-coated pellets, and physical, thermal and mechanical properties of free films as a function of various curing conditions. AAPS PharmSciTech. 2008;9(2):449-57.

39. Okhamafe AO, York P. Effect of solid-polymer interactions on the properties of some aqueous-based tablet film coating formulations II. Mechanical characteristics. Int J Pharm. 1984;22:273-81.

40. Parvin N, Ullah S, Mina F, Gafur A. Structures and mechanical properties of talc and carbon black reinforced high density polyethylene composites: effects of organic and inorganic fillers. J Bangladesh Acad Sci. 2013;37:11-20.

41. Gibson SHM, Rowe RC, White EFT. Mechanical properties of pigmented tablets coating formulations and their resistance to cracking I. Static mechanical measurement. Int J Pharm. 1988;48:63-77.
42. Glaessl B, Siepmann F, Tucker I, Siepmann J, Rades T. Characterisation of quaternary polymethacrylate films containing tartaric acid, metoprolol free base or metoprolol tartrate. Eur J Pharm Biopharm. 2009;73(3):366-72.

43. Gaur PK, Mishra S, Bajpai M, Mishra A. Enhanced oral bioavailability of Efavirenz by solid lipid nanoparticles: in vitro drug release and pharmacokinetics studies. BioMed Res Int. 2014.

44. Gruetzmann R, Wagner KG. Quantification of the leaching of triethyl citrate/polysorbate 80 mixtures from Eudragit RS films by differential scanning calorimetry. Eur J Pharm Biopharm. 2005;60(1):159-62.

45. Lin SY, Chen KS, Run-Chu L. Organic esters of plasticizers affecting the water absorption, adhesive property, glass transition temperature and plasticizer permanence of eudragit acrylic films. J Control Release. 2000;68(3):343-50.

46. Samy W. A study in some transdermal drug delivery systems: Alexandria University; 2001.

47. Karlsson A, Singh SK. Thermal and mechanical characterization of cellulose acetate phthalate films for pharmaceutical tablet coating: effect of humidity during measurements. Drug Dev Ind Pharm. 1998;24(9):827-34.

48. Frohoff-Hulsmann MA, Lippold BC, McGinity JW. Aqueous ethyl cellulose dispersion containing plasticizers of different water solubility and hydroxypropyl methyl-cellulose as coating material for diffusion pellets II: properties of sprayed films. Eur J Pharm Biopharm. 1999;48:67-75. 